\title{
Overview on Pattern identification - history, nature and strategies for treating patients: a narrative review
}

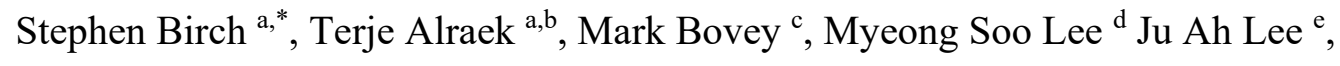 \\ Chris Zaslawski ${ }^{\mathrm{f}}$, Nicola Robinson ${ }^{\mathrm{g}, \mathrm{h}}$, Tae-Hun Kim ${ }^{\mathrm{i}}$, Zhao-xiang Bian ${ }^{\mathrm{j}}$ \\ ${ }^{a}$ Kristiania University College, School of Health Sciences, Oslo, Norway \\ ${ }^{b}$ National Research Centre in Complementary and Alternative Medicine, Faculty of Medicine, \\ Department of Community Medicine, UiT The Arctic University of Norway, Tromso, Norway \\ ${ }^{c}$ Acupuncture Research Resource Centre, British Acupuncture Council, London, UK \\ ${ }^{d}$ Clinical Medicine Division, Korea Institute of Oriental Medicine, Daejeon, Korea \\ ${ }^{e}$ Hwa Pyeong Institute of Integrative Medicine, Incheon, Korea \\ ${ }^{f}$ Chinese Medicine Discipline-Faculty of Science University of Technology Sydney. Australia. \\ ${ }^{g}$ Allied Health Sciences, London South Bank University, London, United Kingdom. \\ ${ }^{h}$ Centre for Evidence-Based Chinese Medicine, Beijing University of Chinese Medicine, Beijing, China \\ ${ }^{i}$ Korean Medicine Clinical Trial Center, Korean Medicine Hospital, Kyung Hee University, Seoul, Korea \\ ${ }^{j}$ Hong Kong Chinese Medicine Clinical Study Centre, School of Chinese Medicine, Hong Kong Baptist \\ University, Hong Kong SAR, China.
}

Short title: Overview on pattern identification

* Corresponding author Stephen Birch, e-mail: sjbirch@gmail.com 


\begin{abstract}
Introduction: In traditional East Asian Medicine (TEAM), various systems of practice exist that have used different theories to guide their practice. Although data gathering has been limited to what can be observed by the four examinations - si zhen, the different systems of practice have focused on different observational data to make diagnostic decisions and choose corresponding treatments. The organization of the data into patterns has led to what is called Pattern Identification based systems of practice (PIs).
\end{abstract}

Methods: The range of systems, theories, treatments and PIs were explored in order to highlight important issues for researchers to consider in performing PI based research

Results: Expert opinions, scholarly and clinical literature on the key issues which compose 'pattern identification' (PI) were identified with respect to the history, development, nature and the different strategies used by different PIs for diagnosing and treating patients.

Conclusion: It is important for researchers to understand these issues so as not to weaken their results and findings, whether conducting survey-based research, clinical trial research, laboratory studies or seeking to influence teaching and practice. This is the first in a series of papers by the international Pattern Identification Network Group (iPING) helping to clarify the area of research on PIs and which seek to expand lines of research on PIs so that teaching, practice, clinical and laboratory research can be more consequential.

Keywords: Pattern identification; syndrome identification; traditional East Asian medicine; narrative review 


\section{Introduction}

The practice of Traditional East Asian Medicine (TEAM) includes treatment methods such as acupuncture \& moxibustion (acumoxa) and herbal medicine, each of which has a long and varied history of use dating from at least the Han dynasty in China (206 BCE-220 CE) [1-4]. In both treatment methods we find descriptions of empirical, less theoretically driven treatments and also more strategic considerations that usually revolve around the theories of TEAM. Empirical approaches in herbal medicine can be found for example, in the Ben Cao, Materia Medica systems, and are not systematically based in theory $[3,5]$. Empirical approaches in acupuncture are also not systematically rooted in theory and involve the description of which acupoints are effective in relieving which symptoms [6-8]. Data is gathered from a patient to help decide treatment by use of the 'naked-senses' [1]. Practice that is more theory driven involves a more systematic assessment of the patient using various naked-sense observations (the four examinations - si zhen), assessment of the combination of observations and reports leading to a diagnostic conclusion, with a treatment tailored to address the symptom complex. In acupuncture the basic theory behind the introduction of needling was summarised in chapter 75 of the Miraculous Pivot from Huangdi's Internal Classic (Huang di nei jing ling shu [Ling shu], circa $100 \mathrm{BCE}$ ) as 'needling regulates the qi' $[9,10]$. A key focus for achieving this is to identify 'What is excess?' (shi) and 'What is deficient (xu)?', so that a matching treatment can be applied: 'If excess then drain it, if vacuous then tonify it.' [8]. Theories of qi amalgamated with the then known anatomical, circulatory and functional systems were combined with environmental theories and lay the foundation for informing judgments of what was wrong with the patient. These theories and their role in diagnosis emerged in the Huangdi's Internal Classic and over time become more systematised. In acupuncture this systematisation becomes clear in the Classic of Difficult Issues (Nan Jing, circa 
100 CE) [11], and for herbal medicine, in the Treatise on Cold Damage (Shang han lun, circa 210

CE) $[5,12]$. Throughout the practice of TEAM systems in East Asia, the role of identifying and treating patterns has had a complex history. In the modern period making the diagnosis based upon patterns of signs and symptoms has become a vital part of TEAM practice. The process of choosing the pattern has different names in different systems and countries [13]. In China's system of 'traditional Chinese medicine,' (TCM), the choice of pattern in diagnosis became formalised as 'bian zheng' often translated as 'pattern identification' with an emphasis on this approach occurring in the post 1950 era in China [14]. The Chinese terminology of bian zheng, 'pattern identification' has become a general term that refers to the process of selecting the pattern and has specific meaning within TCM. Much of the modern focus on diagnosis in TEAM is on this concept and approach, although other systems of TEAM practice have developed diverse approaches which are different [13].

For the purposes of this paper we use the term 'pattern identification systems' (PIs) to include not only the TCM system of 'bian zheng' but also to include those systems that have developed over time in different cultures and contexts to serve different purposes, using varied observation methods guided by different theories. In the sections that follow we explore the purposes of the diagnosis and catalogue some of the variety of different ways that the diagnoses are attained, developed, described and used.

\section{Methods}

Eight of the nine authors are experienced clinicians representing a number of Asian and non-Asian traditions of practice. All nine authors have been involved in PI based research, have published papers on this theme and are members of the international Pattern Identification Network Group 
(iPING) that was established in 2014 after research meetings on pattern identification in Daejeon and Seoul in South Korea. The method we have adopted is an expert opinion-based review of the literature bringing together expertise in scholarly, clinical and research sources to inform our opinions.

\section{Results}

\subsection{Historical overview}

\subsubsection{Diagnostic approaches and the appearance of patterns}

An examination of literature on acupuncture reveals that diagnosis is given or inferred in several parallel types of description and that these have evolved over time.

1. Commenting on the Huangdi's Internal Classic Plain Questions (Huang di nei jing su wen [Su wen]), Paul Unschuld describes how many diagnostic descriptions are given as prognostic indicators to help the practitioner understand what can be treated and when a patient is soon to die [15].

2. Symptom clusters associated with qi related entities, for example the pathways and symptoms of jing mai (channels and collaterals) were first described in Miraculous Pivot (Ling shu) chapter 10 [8]. The structural-functional systems, such as the viscera and bowels (zangfu) had their functions and typical symptoms described in the Internal Classic, for the viscera (zang), see Plain Questions (Su wen) chapter $22[16,17]$ for the bowels $(f u)$ see Miraculous Pivot (Ling shu) chapter four [8, 17].

3. Symptom clusters directly related to treatment via the stated symptomatology associated with the acupuncture points or associated with the individual herbal substance were also described in this historic text. Classification of symptoms associated with the acupuncture 
points emerged after the first descriptions of acupuncture points in the Huangdi's Internal Classic and can be seen in many modern texts $[18,19]$. Classification of symptoms associated with herbal substances started to emerge in the 'Ben Cao', Materia Medica tradition [3].

4. Diagnosis that uses theories of disease associating signs and symptoms with factors were thought to be pathological, like the environmental factors of cold, heat, damp, dryness and wind. Models of this approach emerge within the Huangdi's Internal Classic, Classic of Difficult Issues and Treatise on Cold Damage Diseases [4, 12, 15].

5. The symptom is differentiated according to how it manifests and, with what accompanying signs, so that a tailored treatment can be given. For example, the Miraculous Pivot (Ling shu) chapter 24 describes six types of headache [8], Plain Questions ( $\mathrm{Su}$ wen) chapter 41 describes more than 20 types of low back pain $[16,20]$.

6 Diagnosis that is descriptive of the symptom or cluster of symptoms and their associated treatment were presumably based on experience. This is common in the historical and modern acupuncture literature. For example, the pairs of eight treatment points of the eight extraordinary vessels were first described in 1437 in relation to symptom clusters associated with each pair [21]. As an example of single symptom-diagnoses, the various treatments from modern practitioner Tin Yau So describe symptom-diagnoses and their treatments [7].

7. Diagnosis using theories more systematically by organising signs and symptoms into patterns is additionally informed by treatment principles. For example, the Classic of Difficult Issues (Nan jing) chapter 16 describes patterns of signs and symptoms observed through the four observations and organised by five-phase associations [3]. The Treatise 
on Cold Damage Diseases (Shang han lun) organises herbal prescriptions according to signs and symptoms and how they are classified in a six-level hierarchy $[12,22]$.

Scheid discusses the development of 'zheng', patterns and 'bianzheng', PI with its focus on syndrome differentiation and presents evidence that this is a relatively new focus in the practice of Chinese Medicine in China, most likely emerging as a dominant focus in the 1950s as TCM was developed to help address the complex problem of how to meet the political needs of amalgamating traditional and modern medicine [14]. In a later publication Scheid describes types of zheng patterns that can be found over the last several centuries in China, and presents a table summarising the different types [23]. This table gives a more elaborate description of the diagnostic approaches listed above. As Scheid describes, the different approaches to formulating a diagnosis have been subjected to a variety of different influences including political, ideological and cultural thinking and in recent centuries, the critical eye of and the theories of modern biomedicine.

From the above types of diagnosis that can be found, we see early attempts at organising the signs and symptoms into patterns. Some of these patterns are empirical, presumably based on clinical observation, some are more theoretically guided. The development of PIs over time will have incorporated some from among these different lines of decision making, with theory, observation and experience combining to help create the decision-making processes [24] that organise observed information into diagnostic clinically recognisable patterns. The patterns that emerged in different PIs are organized according to two basic criteria: whether they focus on the symptoms of the patient or not and the intention of the treatment to target the overall health status of the patient or to target symptoms only. 
In the modern period some patterns of diagnosis have focused around the biomedical diagnosis [1-3]. This happens for a number of reasons, such as the desire to fit the TEAM practice within a biomedical framework or setting, in order to encourage insurance reimbursement, the belief systems and training of the individual practitioners, and so on. In other patterns of diagnosis, some formulate the pattern independent of patient symptoms, instead using body signs and other indicators $[1,25]$.

\subsection{Purposes of pattern identification}

\subsubsection{Diagnosis}

\subsubsection{Direct treatment}

Once a diagnosis is determined or a pattern is chosen, a treatment decision automatically follows $[1,13]$. This is expressed by the following term in TCM: 'bianzheng lunzhi' which refers to the idea that one selects treatment based upon the identified pattern [22]. This notion that the treatment follows the pattern is simplified further by some in Japan as 'diagnosis = treatment' [26]. Once a diagnosis has been made there always follows a treatment. Thus, objectively speaking, the diagnosis in TEAM therapies, at the very least, is an important step in choosing a matching treatment for the patient [13].

\subsubsection{Prognosis and assessing patient state and treatment progress}

While the Huangdi' Internal Classic Plain Questions (Su wen) makes a number of prognostic statements related to whether a person may die or be treatable [15], the diagnosis itself can play a prognostic role. For example, the diagnosis of the pattern can be judged according to severity. The more severely the pattern is present, the poorer the prognosis. Additionally, if patients exhibit 
improvement in their symptoms, but show little change in their diagnostic pattern findings, this could also indicate a poorer prognosis for those patients or the need for more treatment. Some patterns are more inherently difficult to treat than others. For example, the pattern of 'blood stasis' has been described as difficult and can take more time to treat [27].

\subsubsection{Indirect treatment}

In some PIs, the identification of the pattern allows the practitioner to make certain recommendations concerning lifestyle, diet, exercise and so on, that are tailored to the patient's individual needs [28-31].

\subsubsection{4-Disease causal explanations}

Other purposes of PIs are less objectively established. The manner of thinking historically in TEAM has been sufficiently different from modern scientific thought such that making the claim that the identified pattern provides a 'causal' description of patient symptoms is problematic [2, 28]. Theories of the 'cause' of disease in TEAM are not sufficiently evidence based to permit statements of disease or symptom causality [13]. In the absence of sufficient evidence, statements of disease or symptom 'cause' in TEAM are better understood as hypotheses about how the problems may have come about and which may inform more refined decision making about treatment targets and techniques. Practically, the identification of the pattern as the 'cause' informs the choice of acupuncture points and techniques and single or combined herbal prescriptions. From a research perspective appropriate hypotheses and methods need to be developed to permit testing of these claims [13]. Some systems of pattern identification, such as Meridian Therapy in Japan explicitly acknowledge the lack of causal relationship between pattern and symptoms, quoting 
Takeyama from 1965 Shudo states "the signs and symptoms are the manifestations, and the primary pattern is the root. These are not in a cause and effect relationship" [17]. Somei Okabe expressed misgivings about the basic Meridian Therapy diagnosis which selects one of four sho or patterns because they are incapable of explaining why a patient becomes ill. He consequently sought to introduce more theory within the system in order to allow practitioners to be able to explain more to their patients why they are ill $[32,33]$.

\subsubsection{Examinations and theories}

Traditionally diagnosis is done according to the four examinations: looking; listening and smelling; asking; palpation. Different authors and different traditions have described these four examinations in ways specific to their system of practice. Each system of practice tends to emphasise some observations over others, each tends to selectively use different examinations and not others. For example, inspection of the tongue body and coating is an important diagnostic method in the system of TCM. Tongue inspection originally developed within herbal medical practice, but in some acupuncture traditions, notably in Japan where herbal medicine cannot be practiced by acupuncturists [25], tongue inspection is generally not used. Abdominal palpation is an important and frequently used method for both herbal medicine and acupuncture practice systems in Japan, but it is not such a frequently used and emphasised method in other systems like TCM [34]. In the Anglo-American system of 'Five Element' acupuncture the main focus is on colour, sound, odour and emotion as the principle observations for deciding the pattern called the 'causative factor' and its treatment $[1,35,36]$.

Sometimes the diagnostic conclusions are arrived at by interpreting the data through the theories of the practice. When this is done signs and symptoms are clustered together into patterns, 
each of which has specific treatments associated with them. Thus, patterns are usually tied to the theory of the practice. Naturally since acupuncture began as a system targeting regulation of qi by tonifying what is deficient and draining what is excess with needles that are applied to the meridian system, then the patterns are related to the meridian system. While in herbal medicine, since the herbs are usually consumed orally and act through the digestive system to affect the rest of the body, the natural focus of theory and patterns is on the viscera and bowels, the internal organ and functional systems [13]. It is also possible that patterns develop over time with additional feedback from observing changes associated with the treatment techniques, which can help inform choice and emphasis of foci among observable findings [24].

\subsubsection{Foci of pattern selection}

Patterns are selected based on the distribution of selective symptoms and signs. As the concept of diagnosis developed, PIs show up in the following two main processes:

a) Symptom centred: In these PIs the pattern is thought or said to be capable of explaining how the symptom occurred - following theoretical descriptions of physiology and pathology. This approach is partially based on the assumption of causal attribution, partially on theoretical and functional hypotheses and partially on experience. In the symptom-centred approach the main symptom must be accounted for, other signs and symptoms are also examined.

b) Non-symptom centred: In these PIs, regardless of the symptoms of the patient, a variety of signs are organised into a pattern. This approach does not necessarily assume causal attribution following instead signs and sometimes symptoms that allow a strategic approach to balancing the body. The goal is to improve the health status of the patient so as to encourage healing and recovery. This approach is partially based on general theory (such as meridian theory) and 
partially on experience. In some systems of practice, the focus is on the pattern from among a limited group of patterns, in others the focus is on selecting from among constitutional types. In the non-symptom-centred approach the symptoms of the patient may be ignored, instead only patient signs are focused on. Symptoms may be used to help make the decision in some cases when it is confusing, but are not the focus for decision making.

Some PIs, notably TCM, are designed to allow the user to use both the symptom centred and non-symptom centred approach. Table 1 gives examples of different PIs. In TCM the 'symptom centred' approach is used in the 'syndrome differentiation' system of the bian zheng $[22,25]$. We use the term 'syndrome differentiation' to refer to the practice that selects the main complaint of the patient and then examines the patient to see which from among a number of potential patterns that are thought causally related to the symptom is best to treat. But the practitioner of TCM can choose to use the non-symptom centred approach as well by focusing on the physiological and pathological states of the patient rather than centring on any particular symptom. Another example of the non-symptom centred approach is the 'sho kettei', 'selection of sho' approach of Meridian Therapy from Japan [17, 26, 37, 38]. In this system it is often said that the 'pattern/diagnosis is not the disease', quoting Fukushima from 1971 Shudo states "The patterns are neither a specific disease nor a name for a certain syndrome. They represent the essence of a pathological disorder and indicate the objective of treatment" [17]. Another example of the nonsymptom centred approach is the Korean system of Sasang Constitutional Medicine of Lee Jaema [39-41]. This system considers that everyone has an original constitution, which manifests in both physiological and pathological signs and symptoms. Within this system it is thus important to determine whether the current problems are physiological or pathological manifestations and to 
treat accordingly with the treatment focusing around the four constitutional diagnoses. A range of signs expressed by the patient are examined to decide the pattern of treatment. Table 1 gives examples of PIs from different systems of practice.

\subsubsection{Root-Branch treatment and PIs}

TEAM practice systems have evolved a two-track treatment approach. In one approach the focus is on correcting the underlying problems described by the practice system, the zhibenfa (Korean bonchibeob, Japanese honchiho) or root treatment. In the other the focus is on applying treatment to improve symptoms directly, the zhibiaofa (Korean pyochibeob, Japanese hyochiho), branch treatment method. Many systems of practice in TEAM use both approaches, while some use only one and sometimes the distinctions are blurred [1, 25, 42].

The root treatment is related to treatment of underlying disturbances (such as regulation of qi) following the theories of the practice, while the branch treatment is related to improvement of the symptom and may use theory but often focuses more on the practitioner's experience. Both the symptom centred and non-symptom centred pattern-based approaches are root treatment approaches, but with different strengths and weaknesses [25]. Potentially the symptom centred root treatment approaches can help the symptoms of the patient improve more quickly since following it, treatment is targeted to affect symptoms directly. On the other hand, for clinical trials, the symptom centred approach may have more difficulty demonstrating the role of the patternbased aspect of treatment when the primary outcome measure is the symptom, since there will be difficulty separating effects of the root treatment and branch treatment, both of which target the primary outcome target, the symptom. Conversely, the non-symptom centred root treatment approach may be slower to create changes in the symptom in clinical trials, as it more indirectly influences the primary outcome of the symptom- attempting to improve first the physiological 
state of the patient, in the hope that this helps the body recover from the symptom. On the other hand, the non-symptom centred root treatment approach may be more helpful for demonstrating the role of pattern-based treatment within the trial especially if the symptom (branch) treatment is not applied as might occur in certain clinical contexts [25]. Table 1 gives examples from the Chinese TCM system, the Japanese Meridian Therapy system, the Korean Sasang Constitutional Medicine system, the Korean Sa'am acupuncture system and the Euro-American system of 'Five Element' acupuncture to illustrate these issues. Systems of TEAM practice that are more branch treatment focused, describing treatments according to the symptoms, such as those described in items 3 and 6 in section 3.1.1 above, do not generally belong within the class of PI-based treatment systems.

Table 2 gives examples of the different theoretical foci, diagnostic and treatment foci and development timelines of the TCM, Meridian Therapy, Sasang Constitutional Medicine, Sa'am acupuncture and Five Element systems from China, Japan, Korea and Euro-America respectively.

\subsubsection{8, Education and clinical practice}

TEAM practice systems are usually learned in specialised educational programs and teaching institutions. Some teach single practice systems each with its own PI system, some teach more than one practice system with different PI systems. Once in clinical practice, it is common for practitioners to learn additional systems. In traditional Korean medicine (TKM), several different systems of thinking and practice might be learned and used, the choice of which to use and whether and how to combine them being up to the individual practitioner, influenced by many factors [43]. Surveys of practice in the UK show similar trends, with many people practicing more than one TEAM based approach each with its own PI system [50-52]. Do practitioners learn additional 
systems of practice because they feel their original studies were insufficient for clinical practice or they do not like those practice systems? Do they choose to learn additional systems because they identified weaknesses within their original system of study and sought to address those weaknesses? Do they study additional PIs to match the system of PI associated with specific treatment systems, such as TCM approaches for herbal medicine and Meridian Therapy for acupuncture? These are some possibilities that may explain the range of usage of PIs in clinical practice.

These considerations raise questions about how systems are taught and how systems are practiced. There are insufficient studies in both these areas to have clear understanding of how practitioners arrive at their decisions on what to do and how to use PIs in their practice. We also find evidence of specialisation within the range of possible practice approaches. There are some practitioners that focus on specific herbal medicine treatment systems such as that of the Shanghan Lun, some that focus on specific acupuncture treatment systems $[17,26,53]$. If we are to study PIs in scientific studies, we need to make these issues clear and perform preliminary studies to understand more about how PIs are taught and practiced. It is important that more survey studies are performed to help provide answers to these questions [52].

\subsubsection{Ontology}

Various authors have contrasted thinking in traditional East Asian medicine with thinking in Western Medicine. This is not simple because there has likely been an influence in both an Eastward transmission as well as a Western transmission. Probably the 'mangle of practice' approach [54] to investigating, uncovering and describing similarities and differences between the two medical systems will be necessary $[14,55,56]$. But since few have performed detailed 
historical or anthropological analyses, we can make only approximate generalisations at this time. Birch and Lewith partially addressed this issue in the overview of historical development and thinking [2]. This contrast of thinking is important to bear in mind because it is normal for modern science and medicine to ask the following types of questions about TEAM diagnoses:

a) Do the patterns really exist?'

b) What are the diagnostic criteria for such patterns?

c) Are these criteria well recognized and applied?

d) Is the diagnostic process the same for all TEAM practitioners?

e) Do all practitioners follow the same diagnostic criteria?

f) Do all practitioners fully follow the diagnostic criteria?

g) Is pattern diagnosis really a key factor for the outcome of treatment?

h) Can diagnosis of pattern be repeatable for a certain stage of disease? [57]

i) How can you explain the differences between PI systems when examining same patient?

j) How has training influenced future practice of PI

These lead to further questions on how to proceed with research on PI: What are the most important questions in practice and in research for PI? How to prioritize research in this area?

Most of these issues are addressed in parallel publications in this Special Issue, here we feel it helpful to address the first question: Do the patterns really exist? For many scientists if the pattern is not found to 'exist' then addressing the other questions probably becomes irrelevant and unnecessary. Thus, it is important to address this question first. 
What does it mean for a pattern to 'really exist'? This is a notion that borrows from modern science which seeks to establish the objective reality of things using multiple acceptable and established methods of investigation.

\subsubsection{TEAM based pattern identification versus Western medical diagnosis}

In modern medicine the diagnosis of pulmonary tuberculosis is established according to the following criteria:

The patient reports symptoms such as cough especially with signs of blood in sputum, chest pain, fatigue and weight loss. There is a positive TB skin test, positive blood serum test and positive sputum test with evidence on an x-ray of the lungs of characteristic dark spots on the lungs. Each method of investigation employs technologies that have been subjected to multiple testing methods to verify that what is being observed or measured falls within acceptable limits of the findings of those tests. Each process has been tested and agreed upon by multiple sources. Each observation of measurement has been tested to show that it is repeatable and reliable. Each is considered to describe objective facts, each of which can have decades of multiple lines of research behind it. The diagnosis of pulmonary tuberculosis is thus objectively established and is said to really exist in that patient.

Contrast this with the diagnosis of blood stasis pattern an important pattern in TEAM and described in the recently released WHO ICD-11 codes [58]. Within the practice of TCM, the definition of blood stasis is not yet clearly agreed upon and thus not yet standardised [59], the signs and symptoms of blood stasis are not yet agreed upon in texts books in China [59] or among Asian countries [60-62]. These findings suggest that the diagnosis of blood stasis does not yet have an 
objective basis, research to establish it objectively and about its nature are still developing [59, 63].

We thus see a stark contrast between the diagnosis of the biomedical disease category of pulmonary tuberculosis and the traditional pattern of 'blood stasis.' The former is established according to multiple lines of research and validation and refers to a medical condition considered to have been objectively established. The latter is a practical concept generally agreed upon as a useful target for treatment, but which does not yet have internationally established criteria for its description, may necessarily retain TEAM system-specific variation and which thus cannot be considered as having an objective basis. By the standards that many scientists might say something is 'real', the former is considered to be 'real'. By these same standards the latter might be said to not be 'real'. However, as we pointed out in the opening sections above, the PI based diagnosis always comes with treatment options, so it can be fundamentally considered to be a reasoning and analytic approach that aids the practitioner to choose a treatment or narrow down from among treatment options. In this sense the pattern can be 'real' as a process-oriented diagnosis in contradistinction to the more structure-oriented diagnosis of the former. This is similar to the distinction between the easily measured and demonstrable 'hardware' of a computer and the nonvisible 'software' of the computer [64]. Citing physicist Davies [65], Manaka describes how 'software laws' exist that govern the behaviour of organization, information and complexity and that are not derivable from the hardware which is subject to different sets of laws, "software laws apply to emergent phenomena, inducing their appearance and controlling the form and behaviour" [64]. TEAM descriptions of the body and their associated diagnostic patterns may be more like software that helps the practitioner focus the treatment to match the patient. Modern medical diagnoses seek to find the disease which has the same kind of ontological status as the hardware 
of the computer, while in the absence of this kind of evidential base, TEAM based diagnosis, focusing on PI, may be more like deciding the pattern that permits the most clinically useful way forward, where the pattern has the same ontological status as the 'software'. Thus, two distinct lines of investigation may be needed to explore PI based diagnoses:

- Efforts that seek to establish an objective basis of each pattern - hardware-based approach

- Efforts that seek to establish that the methods of observation, the reasoning and judgments based on those observations yield practical tools that allow selection of treatments that yield better outcomes - software-based approach

What lines of investigation and research will be necessary if these two approaches are to be pursued? We find suggestions for this by looking at the field of psychology. The field of psychology has faced similar issues. When psychological disorders were first defined, the fields of biology and neuroscience were not sufficiently advanced to permit detailed hardware-like descriptions of the problems, thus the early focus on research was to establish agreement of what is being diagnosed so that treatment could be reliably identified, tested and decided upon. It was with the publication of the first Diagnostic and Statistical Manual of Mental Disorders (DSM) in the 1950s that psychological disorders first started to become accepted and recognised by mainstream medicine [66]. Studies to establish reliability and validity of observations and judgments form the core of this approach. Now with developments in fields like the neurosciences, additional biological criteria have been found to extend the ontological status of diagnostic categories from more software-like to more hardware-like descriptions. Perhaps PI based diagnoses in TEAM should follow similar research strategies. With the increasing attention to and use of PI in clinical research found by Zhang et al. in their review of WHO registered trials of TCM - in this collection [67], there is an increasing need to find solutions to these issues on PI. 


\section{Summary}

From the above review of the history of different diagnoses in TEAM, including the development of PIs, and the examples of different PIs with their varied emphases and foci, we can see that researchers need to be careful to make explicit and transparent what is being studied and ensure that it is sufficiently identified and documented. It is also important to not make inappropriate assumptions about the nature of what is being studied, for example about causality and ontological status of the patterns. These are both rich and complex areas for further research.

\section{Overview of PI for research and investigation}

From the above considerations we can see that a number of different factors have been identified to understand and investigate in order for research on PI to move forward. To date little research has been done to validate PIs for research, education or practice $[68,69]$. Educational issues need to be better understood, and as research proceeds, results from studies need to be brought back to inform and improve education of PI based systems. How PIs are used in clinical practice needs to be made clearer so that scientific studies can be made more relevant to clinical practice, results from studies can then be used to inform clinical practice. Figure 1 proposes a range of factors likely to play a role in both historical and currently practised systems of pattern identification. One aspect of practice is called 'clinical reasoning'. It is beyond the scope of this paper to explore this further, its role in TCM was described by Zaslawski [70] and more recently Kim et al. have elaborated on this with regards the practice of traditional Korean medical systems. In parallel papers we will present data from a survey about clinical practice, we will discuss issues related to PIs in clinical practice and issues around how PIs are taught within educational programs. In addition, we will 
also examine the use of PIs in clinical trials as a baseline for examining PIs in clinical research, and will describe research needs for examining the use of PI in clinical research and laboratory research.

\section{Funding}

This study was supported by Korea Institute of Oriental Medicine (K13130, K14281, K15111). Prof. Nicola Robinson (visiting professor of Beijing University of Chinese Medicine) is funded by Overseas Expertise Project, Ministry of Education of China（G20190001122）

\section{Declarations of competing interest}

None

\section{Acknowledgements}

None

\section{Data availability}

There is no available data related to this article. 


\section{References}

[1] S. Birch, R.L. Felt, Understanding acupuncture, Elsevier Health Sciences 1999.

[2] S. Birch, G. Lewith, Acupuncture research: The story so far, Acupuncture research, Elsevier 2008, pp. 15-35.

[3] P. Unschuld, Medicine in China: History of Pharmaceutics, University of California Press 1986.

[4] P.U. Unschuld, Medicine in China: A history of ideas, Univ of California Press 2010.

[5] S. Birch, M.Á.C. Mir, M. Rodriguez, Restoring Order in Health and Chinese Medicine: Studies of the Development and Use of Qi and the Channels, La Liebre de Marzo 2014.

[6] M. Huangfu, S.-z. Yang, C. Chace, The Systematic Classic of Acupuncture \& Moxibustion, Blue Poppy Enterprises, Inc.1994.

[7] J.T.Y. So, Treatment of disease with acupuncture, Paradigm Publications 1987.

[8] P.U. Unschuld, Huang Di Nei Jing Ling Shu: The Ancient Classic on Needle Therapy, Univ of California Press 2016.

[9] S. Birch, The jingmai and qi: acupuncture perspectives, Restoring order in health and Chinese medicine: Studies of the development and use of qi and the channels. Barcelona (Spain): La Liebre \& Jade Stone Group (2014) 183-266.

[10] E.R. de la Vallée, A Study of Qi: In Classical Texts, Monkey Press 2006.

[11] P.U. Unschuld, Nan-ching the classic of difficult issues, Univ of California Press 1986.

[12] Z. Zhang, F. Ye, N. Wiseman, C. Mitchell, Y. Feng, Shang Han Lun (on cold damage): translation and commentaries, 1999. 
[13] S. Birch, T. Alraek, Traditional East Asian medicine: How to understand and approach diagnostic findings and patterns in a modern scientific framework?, Chinese journal of integrative medicine 20(5) (2014) 336-340.

[14] V. Scheid, Chinese medicine in contemporary China: plurality and synthesis, Duke University Press 2002.

[15] P.U. Unschuld, Huang Di Nei Jing Su Wen: Nature, Knowledge, Imagery in an Ancient Chinese Medical Text: With an appendix: The Doctrine of the Five Periods and Six Qi in the Huang Di Nei Jing Su Wen, Univ of California Press 2003.

[16] P.U. Unschuld, H. Tessenow, Z. Jinsheng, Huand Di Nei Jing Su Wen: An Annotated Translation of Huang Di's Inner Classic - Basic Questions, University of California Press, Berkeley, 2011.

[17] S. Denmei, Introduction to meridian therapy, Eastland Press, Seattle, WA, 1990.

[18] J.T.Y. So, Book of Acupuncture Points. Brookline, Massachusetts, Paradigm Publications, 1985.

[19] D. Shudo, S. Brown, Finding Effective Acupuncture Points, Eastland Press, Seattle USA, 2003.

[20] S.J. Liao, Acupuncture for low back pain in Huang Di Nei Jing Su Wen, Acupuncture \& electro-therapeutics research 17(4) (1992) 249-258.

[21] K. Matsumoto, S. Birch, Extraordinary vessels, Paradigm Publications 1986.

[22] N. Wiseman, A practical dictionary of Chinese medicine, paradigm publications 1998.

[23] V. Scheid, Patterns, Syndromes, Types: Who Should We Be and What Should We Do?, Eur. J. Oriental Med 11 (2014). 
[24] S. Birch, Treating the patient not the symptoms: Acupuncture to improve overall healthEvidence, acceptance and strategies, Integrative Medicine Research 8(1) (2019) 33-41.

[25] S. Birch, M.S. Lee, T. Alraek, T.-H. Kim, Overview of treatment guidelines and clinical practical guidelines that recommend the use of acupuncture: a bibliometric analysis, The Journal of Alternative and Complementary Medicine 24(8) (2018) 752-769.

[26] K. Fukushima, Meridian therapy: a hands-on text on traditional Japanese hari based on pulse diagnosis, Toyo Hari Medical Association 1991.

[27] Y. Manaka, Papers on the nature, signs and treatment of oketsu (blood stasis) from 1941 to the present, originally published in many journals and collected in Manaka Yoshio Ronbunshu (Collected Essays of Manaka Yoshio), 15th Anniversary Issue of the Shinkyu Topology Gakkai, Kyoto (1988) 54-101.

[28] S. Birch, B.M. Qi, jingmai: Scientific investigation of concepts based in traditional east asian medicine: Challenges to cross-paradigm research, Restoring order in health and Chinese medicine: Studies of the development and use of qi and the channels. Barcelona (Spain): La Liebre \& Jade Stone Group (2014) 376-399.

[29] H. MacPherson, B. Elliot, A. Hopton, H. Lansdown, S. Birch, C. Hewitt, Lifestyle advice and self-care integral to acupuncture treatment for patients with chronic neck pain: secondary analysis of outcomes within a randomized controlled trial, The Journal of Alternative and Complementary Medicine 23(3) (2017) 180-187.

[30] H. MacPherson, K. Thomas, Self-help advice as a process integral to traditional acupuncture care: implications for trial design, Complementary therapies in medicine 16(2) (2008) 101-106.

[31] C. Paterson, P. Dieppe, Characteristic and incidental (placebo) effects in complex interventions such as acupuncture, BMJ 330(7501) (2005) 1202-1205. 
[32] S. Okabe, Introduction to traditional Japanese acupuncture (meridian therapy), N. Am. J. Orient. Med 5 (1998) 9-13.

[33] S. Okabe, Introduction to traditional Japanese acupuncture (part 2), N. Am. J. Orient. Med 5 (1998) 3-6.

[34] N. Wiseman, A. Ellis, Fundamentals of Chinese Medicine: Zhong Yi Xue Ji Chu Paradigm Publications, Brookline, MA 1985.

[35] J.R. Worsley, Is Acupuncture for You, College of Traditional Chinese Acupuncture, Leamington Spa, England 1973.

[36] D.M. Connelly, Traditional acupuncture: The law of the five elements, Centre for Traditional Acupuncture 1979.

[37] S. Okabe, Shinkyu Keiraku Chiryo, Kobunsha, Tokyo 1974.

[38] S. Honma, Keiraku Chiryo Kouwa - Lectures on Meridian Therapy, Yi do no Nippon Sha, Yokosuka 1949.

[39] J. Lee, J. Lee, H. Shin, K.-S. Kim, E. Lee, B. Koh, H.-J. Jang, Suggestion of new possibilities in approaching individual variability in appetite through constitutional typology: a pilot study, BMC complementary and alternative medicine 12(1) (2012) 122.

[40] Y.-H. Kim, S.W. Shin, M.-W. Hwang, Morality and longevity in the viewpoint of Sasang medicine, Integrative medicine research 4(1) (2015) 4-9.

[41] H. Chae, S. Lee, S.H. Park, E. Jang, S.J. Lee, Development and validation of a personality assessment instrument for traditional Korean medicine: Sasang personality questionnaire, Evidence-Based Complementary and Alternative Medicine 2012 (2012). 
[42] R. Schnyer, S. Birch, H. MacPherson, Acupuncture practice as the foundation for clinical evaluation, Acupuncture research: strategies for building an evidence base. London: Elsevier (2007) 153-179.

[43] R. Okitsu, K. Iwasaki, Y. Monma, S. Takayama, S. Kaneko, G. Shen, M. Watanabe, T. Kamiya, A. Matsuda, A. Kikuchi, Development of a questionnaire for the diagnosis of Qi stagnation, Complementary therapies in medicine 20(4) (2012) 207-217.

[44] M.M. Ko, J.A. Lee, M.H. Cha, B.-K. Kang, M.S. Lee, Stroke in traditional Korean medicine: a nine-year multicentre community-based study in South Korea, Scientific reports 6 (2016) 28286. [45] I.-b. Song, F.E. Sandoval, An introduction to Sasang constitutional medicine, Jimoondang 2005.

[46] S. Lee, S. Hahn, S. Kim, Saam five element acupuncture, Seoul: Jimoondang 2009.

[47] Anonymous, Essentials of Chinese Acupuncture, Foreign Languages Press, Beijing 1980.

[48] X. Cheng, Chinese Acupuncture and Moxibustion Foreign Language Press Beijing, 1987.

[49] A. Ellis, N. Wiseman, K. Boss, Fundamentals of Chinese Acupuncture, Paradigm Publications, Brookline, MA 1988.

[50] A. Hopton, S. Curnoe, M. Kanaan, H. MacPherson, Acupuncture in practice: mapping the providers, the patients and the settings in a national cross-sectional survey, BMJ Open 2(1) (2012) e000456.

[51] M. Bovey, A. Lorenc, N. Robinson, Extent of acupuncture practice for infertility in the United Kingdom: experiences and perceptions of the practitioners, Fertility and sterility 94(7) (2010) $2569-2573$. 
[52] N. Robinson, M. Bovey, J.A. Lee, C. Zaslawski, P. Tian, T.-H. Kim, T. Alraek, Z.-X. Bian, M.S. Lee, S. Birch, How do acupuncture practitioners use pattern identification-An international web-based survey?, European Journal of Integrative Medicine 32 (2019) 100997.

[53] J.-Y. Wang, J.D. Robertson, Applied channel theory in Chinese medicine: Wang Ju-Yi's lectures on channel therapeutics, Eastland Press 2008.

[54] A. Pickering, The mangle of practice: Time, agency, and science, University of Chicago Press 2010.

[55] J. Kim, Beyond paradigm: Making transcultural connections in a scientific translation of acupuncture, Social Science \& Medicine 62(12) (2006) 2960-2972.

[56] S. Birch, Explanatory nature, models, needs and requirements for testing them, in: Proceedings of the International Symposium on Theory and Evidence for Acupuncture, Nanyang Technological University, Singapore 2013.

[57] Q. Guo, Q. Chen, Standardization of syndrome differentiation defined by traditional chinese medicine in operative breast cancer: a modified delphi study, The Scientific World Journal 2015 (2015).

[58] World Health Organization, ICD-11codes - 26 Traditional medicine conditions module 1. Available at: $\quad$ https://icd.who.int/browse11/1m/en\#/http\%3a\%2f\%2fid.who.int\%2ficd\%2fentity\%2f718687701.

[59] T.-Y. Choi, J.H. Jun, B. Park, J.A. Lee, S. You, J. Jung, M.S. Lee, Concept of blood stasis in Chinese medical textbooks: a systematic review, European Journal of Integrative Medicine 8(3) (2016) 158-164. 
[60] J.A. Lee, B.-K. Kang, T.-Y. Park, H. Lee, J.-I. Kim, S.-U. Park, J. Lee, B.-C. Shin, J.-H. Lee, S.-S. Son, CoRe-Ditec-BS (convergence research of the diagnostic technology for blood stasis): study protocol, European Journal of Integrative Medicine 7(4) (2015) 417-422.

[61] S.-m. Li, H. Xu, K.-j. Chen, The diagnostic criteria of blood-stasis syndrome: considerations for standardization of pattern identification, Chinese Journal of Integrative Medicine 20(7) (2014) 483-489.

[62] K. Terasawa, H. Shinoda, A. Imadaya, H. Tosa, M. Bandoh, N. Satoh, The presentation of diagnostic criteria for “Oketsu” syndrome, Kampo Medicine 34(1) (1983) 1-17.

[63] J. Liao, J. Wang, Y. Liu, J. Li, L. Duan, G. Chen, J. Hu, Modern researches on Blood Stasis syndrome 1989-2015: A bibliometric analysis, Medicine 95(49) (2016).

[64] Y. Manaka, S. Birch, K. Itaya, Chasing the dragon's tail: the theory and practice of acupuncture in the work of Yoshio Manaka, Paradigm Publications 1995.

[65] P. Davies, The Cosmic Blueprint, Simon and Schuster, New York, NY 1988.

[66] S. Hoerman, C.E. Zupanick, M. Dombeck, MentalHealth.net. Available at https://www.mentalhelp.net/articles/the-history-of-the-psychiatric-diagnostic-system-continued/, (2013).

[67] X. Zhang, R. Tian, C. Zhao, S. Birch, J.A. Lee, T. Alraek, M. Bovey, C. Zaslawski, N. Robinson, T.H. Kim, M.S. Lee, Z.X. Bian. The use of pattern differentiation in WHO-registered traditional Chinese medicine trials - A systematic review. European Journal of Integrative Medicine 30 (2019) 100945. https://doi.org/10.1016/j.eujim.2019.100945 
[68] M. Popplewell, J. Reizes, C. Zaslawski, Consensus in Traditional Chinese Medical diagnosis in open populations, The Journal of Alternative and Complementary Medicine 25(11) (2019) $1109-1114$.

[69] K.A. O'Brien, S. Birch, A review of the reliability of traditional East Asian medicine diagnoses, The journal of alternative and complementary medicine 15(4) (2009) 353-366.

[70] C. Zaslawski, Clinical reasoning in traditional Chinese medicine: implications for clinical research, Clinical Acupuncture and Oriental Medicine 4(2-3) (2003) 94-101. 


\section{Figure captions}

Figure 1 Overview of factors that influence the development and use of PI and associated research areas 


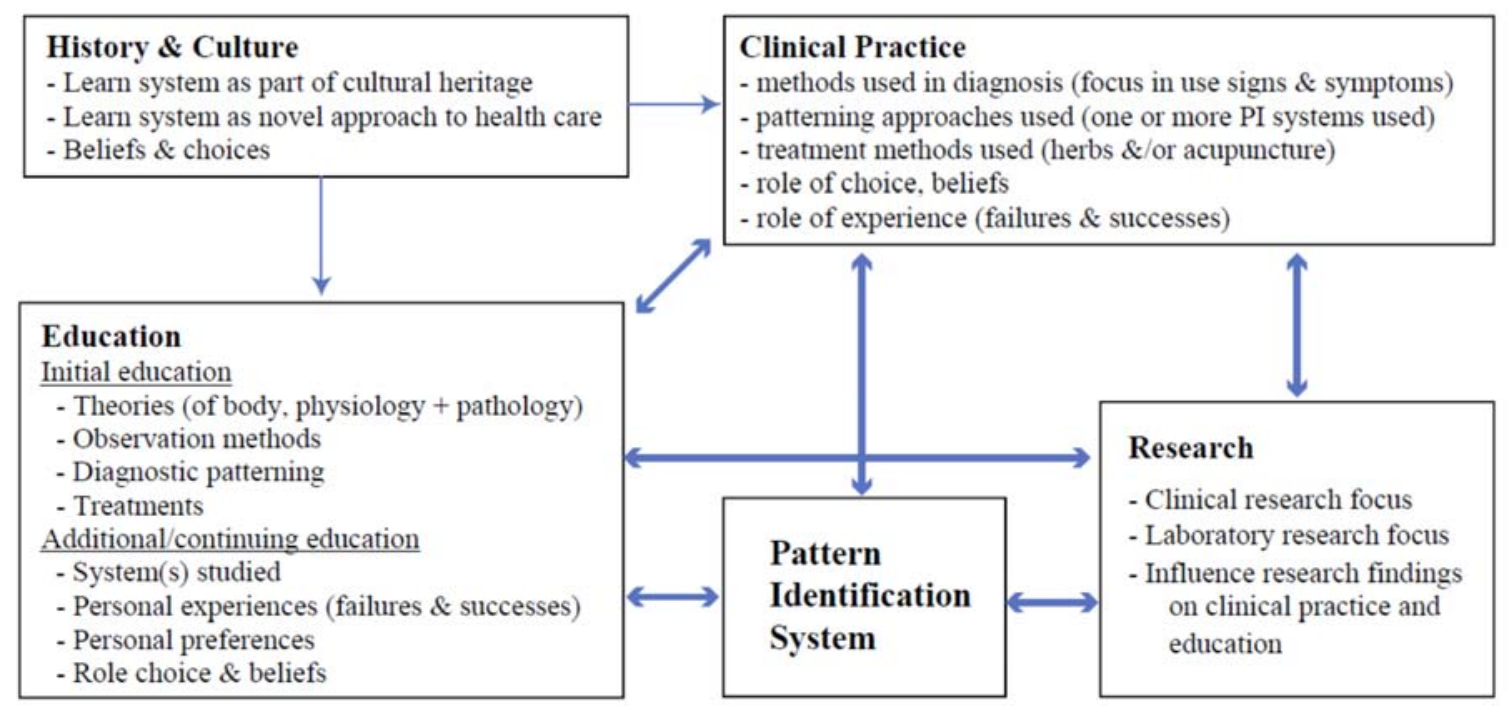


Table 1. Examples of patterns in different PIs.

\begin{tabular}{|c|c|c|c|c|c|}
\hline $\begin{array}{l}\text { Practice } \\
\text { System }\end{array}$ & $\begin{array}{l}\text { Pattern/ } \\
\text { symptom } \\
\text { pattern } \\
\text { focus }\end{array}$ & Patterns & $\begin{array}{l}\text { Signs-symptoms } \\
\text { (number) }\end{array}$ & Treatment & Source \\
\hline $\mathrm{TCM}$ & $\begin{array}{l}\text { Non- } \\
\text { symptom } \\
\text { centred }\end{array}$ & Qi stagnation & $\begin{array}{l}\text { main signs and } \\
\text { symptoms (23) }\end{array}$ & $\begin{array}{l}\text { Herbs }+ \\
\text { acupuncture }\end{array}$ & [43] \\
\hline TCM & $\begin{array}{l}\text { Symptom } \\
\text { centred } \\
\text { (Stroke) }\end{array}$ & $\begin{array}{l}\text { Fire heat; } \\
\text { Dampness phlegm; } \\
\text { Qi deficiency; } \\
\text { Yin deficiency }\end{array}$ & $\begin{array}{l}\text { Fire heat (19) } \\
\text { Dampness phlegm } \\
\text { (7) } \\
\text { Qi deficiency (11) } \\
\text { Yin deficiency (7) }\end{array}$ & $\begin{array}{l}\text { Herbs }+ \\
\text { acupuncture }\end{array}$ & [44] \\
\hline $\begin{array}{l}\text { Meridian } \\
\text { Therapy }\end{array}$ & $\begin{array}{l}\text { Non- } \\
\text { symptom } \\
\text { centred }\end{array}$ & Lung vacuity & $\begin{array}{l}\text { Right cun and } \\
\text { guan deep pulses } \\
\text { weak + palpable } \\
\text { reaction to right } \\
\text { side of navel (2) }\end{array}$ & Acupuncture & {$[26]$} \\
\hline Sasang & $\begin{array}{l}\text { Non- } \\
\text { symptom } \\
\text { centred }\end{array}$ & $\begin{array}{l}\text { Soeum syndrome } \\
\text { Soyang syndrome; } \\
\text { Tae-eum syndrome } \\
\text { Taeyang syndrome }\end{array}$ & $\begin{array}{l}\text { Soeumin } \\
\text { symptomatology } \\
(16) \\
\text { Soyangin } \\
\text { symptomatology } \\
(15) \\
\text { Tae-eumin } \\
\text { symptomatology } \\
(13) \\
\text { Taeyangin } \\
\text { symptomatology } \\
\text { (6) }\end{array}$ & Herbs & [45] \\
\hline Sa'am & $\begin{array}{l}\text { Symptom } \\
\text { centred }\end{array}$ & $\begin{array}{l}\text { Deficiency and excess in five viscera } \\
\text { and six bowels }\end{array}$ & $\begin{array}{l}\text { main signs and } \\
\text { symptoms (43) }\end{array}$ & Acupuncture & [46] \\
\hline $\begin{array}{l}\text { Five } \\
\text { Element }\end{array}$ & $\begin{array}{l}\text { Non- } \\
\text { symptom } \\
\text { centred }\end{array}$ & $\begin{array}{l}\text { 'Causative Factor' in one of five } \\
\text { elements or one of } 12 \text { organs/officials }\end{array}$ & $\begin{array}{l}\text { colour, sound, } \\
\text { emotion, odour (4) }\end{array}$ & Acupuncture & {$[35,36]$} \\
\hline
\end{tabular}


Table 2. Examples of different schools of acupuncture and herbal medicine: their theories, diagnostic and treatment foci.

\begin{tabular}{|c|c|c|c|c|}
\hline Practice system & Theoretical foci & Diagnostic foci & $\begin{array}{l}\text { Treatment } \\
\text { foci }\end{array}$ & Historical origins \\
\hline $\begin{array}{l}\text { TCM } \\
(1)\end{array}$ & $\begin{array}{l}\text { zang-fu; qi-blood; jin- } \\
\text { ye; 8-principles - yin- } \\
\text { yang theory; etc. }\end{array}$ & $\begin{array}{l}\text { Primarily by questioning, with } \\
\text { visual inspection (eg tongue) } \\
\text { and palpation of the body and } \\
\text { pulses - zang-fu/qi-blood/8 } \\
\text { principles [34] } \\
\text { More than } 100 \text { distinct patterns } \\
\text { [34] }\end{array}$ & $\begin{array}{l}\text { Herbal } \\
\text { medicine } \\
\text { prescriptions } \\
\& / \text { or } \\
\text { acupuncture } \\
\text { treatment }\end{array}$ & $\begin{array}{l}\text { Practical combination of modern medical, } \\
\text { traditional herbal and acupuncture } \\
\text { systems. } \\
\text { Emerged in China in the mid-1950s in } \\
\text { response to political and public health } \\
\text { needs [11] }\end{array}$ \\
\hline $\begin{array}{l}\text { Meridian Therapy } \\
\text { (2) }\end{array}$ & $\begin{array}{l}12 \text { channels; yin-yang } \\
\text { theory; } 5 \text { phase } \\
\text { theory; qi circulation }\end{array}$ & $\begin{array}{l}\text { Using especially pulse and } \\
\text { abdominal palpation diagnosis, } \\
\text { identify the primary five-phase } \\
\text { deficiency pattern, among } 6 \text { yin } \\
\text { meridians [17] } \\
4 \text { 'primary' patterns with a small } \\
\text { number of secondary patterns } \\
{[17,26]}\end{array}$ & $\begin{array}{l}\text { Acupuncture } \\
\text { treatment }\end{array}$ & $\begin{array}{l}\text { Practical interpretation of passages in the } \\
\text { Nanjing. } \\
\text { Emerged in Japan in the mid-1930s in } \\
\text { response to Japanese government efforts } \\
\text { to eliminate traditional medical thinking } \\
\text { [1] }\end{array}$ \\
\hline $\begin{array}{l}\text { Sasang }-4 \\
\text { Constitutions (3) }\end{array}$ & $\begin{array}{l}\text { Classification of } \\
\text { constitutional types } \\
\text { according to a four- } \\
\text { fold typography } \\
\text { (tae-yang / so-yang / } \\
\text { tae-eum / so-eum) }\end{array}$ & $\begin{array}{l}\text { Observation of body } \\
\text { characteristics, personality traits } \\
\text { and disease symptoms to } \\
\text { identify the constitutional type } \\
\text { (Sasangin) } \\
4 \text { basic patterns }\end{array}$ & $\begin{array}{l}\text { Herbal } \\
\text { medicine } \\
\text { prescriptions }\end{array}$ & $\begin{array}{l}\text { Began as a theoretical reconstruction of } \\
\text { historical ideas and medical practice } \\
\text { systems } \\
\text { Emerged in Korea in the late } 1890 \text { s }\end{array}$ \\
\hline Sa'am (4) & $\begin{array}{l}12 \text { channels; yin-yang } \\
\text { theory; } 5 \text { phase theory }\end{array}$ & $\begin{array}{l}\text { Observation of specific body } \\
\text { symptoms and location of the } \\
\text { lesion }\end{array}$ & $\begin{array}{l}\text { Acupuncture } \\
\text { treatment }\end{array}$ & $\begin{array}{l}\text { Developed in the late } 16^{\text {th }} \text { century in } \\
\text { Korea }\end{array}$ \\
\hline Five Element (5) & $\begin{array}{l}\text { Five elements and } \\
\text { twelve meridians }\end{array}$ & $\begin{array}{l}\text { Colour, sound, odour, emotion } \\
\text { and the pulses [36] }\end{array}$ & $\begin{array}{l}\text { Acupuncture } \\
\text { treatment }\end{array}$ & Developed in the $1960 \mathrm{~s} / 1970 \mathrm{~s}$ in the UK \\
\hline
\end{tabular}

(1) for example: Anonymous [47], Cheng [48], Ellis et al.[49]; (2) for example: Fukushima [26], Honma [38], Okabe [37], Shudo [17];

(3) for example: Chae et al. [41], Lee et al. [39], Song [45] (4) for example Lee et al. [46] (5) for example: Connelly [36], Worsley [35]. 